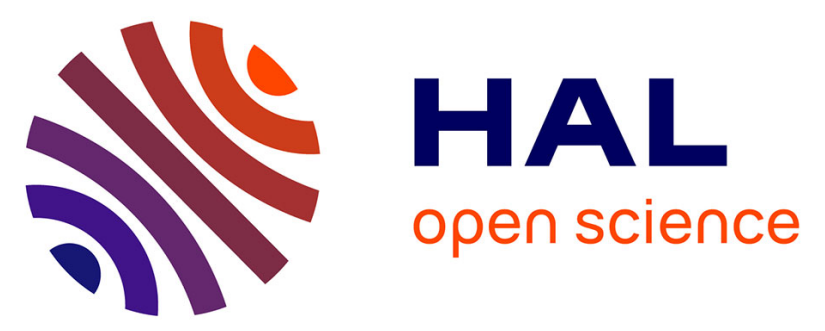

\title{
Synthesis of 2-Substituted Indoles through Cyclization and Demethylation of 2-Alkynyldimethylanilines by Ethanol
}

Guangkuan Zhao, Christelle Roudaut, Vincent Gandon, Mouad Alami, Olivier Provot

\section{To cite this version:}

Guangkuan Zhao, Christelle Roudaut, Vincent Gandon, Mouad Alami, Olivier Provot. Synthesis of 2Substituted Indoles through Cyclization and Demethylation of 2-Alkynyldimethylanilines by Ethanol. Green Chemistry, 2019, 21 (15), pp.4204-4210. 10.1039/C9GC01880H . hal-02394149

\section{HAL Id: hal-02394149 https://hal.science/hal-02394149}

Submitted on 4 Dec 2019

HAL is a multi-disciplinary open access archive for the deposit and dissemination of scientific research documents, whether they are published or not. The documents may come from teaching and research institutions in France or abroad, or from public or private research centers.
L'archive ouverte pluridisciplinaire HAL, est destinée au dépôt et à la diffusion de documents scientifiques de niveau recherche, publiés ou non, émanant des établissements d'enseignement et de recherche français ou étrangers, des laboratoires publics ou privés. 


\section{Synthesis of 2-Substituted Indoles through Cyclization and Demethylation of 2-Alkynyldimethylanilines by Ethanol}

Received 00th January 20xx, Accepted 00th January 20xx DOI: $10.1039 / \times 0 \times x 00000 x$
Herein, we demonstrated that 2-alkynyldimethylamines easily cyclize in EtOH according to a 5-endo-dig annulation into 2substituted indoles without the aid of any additive or any metal catalyst to activate the triple bond. Thus, a variety of functionalized 2-styrylindoles, 2-arylindoles, 2-alkynylindoles, and 2-alkylindoles were prepared in high to excellent yields according to an environmentally friendly protocol. The mechanism has been explored to better understand this eco-friendly access to 2substituted indoles and DFT computations rationalized the role of the solvent in this $\mathrm{N}$-annulation/dealkylation process.

\section{Introduction}

Indoles are important heterocycles in biologically active natural products $^{1}$ and are also frequently found in various pharmaceutical products. ${ }^{2,3}$ Consequently, this important structural motif has led to the development of a very large number of synthetic methodologies. Among them, the 5-endodig hetero-annulation of alkynyldimethylanilines in the presence of electrophiles $\left(\mathrm{ICl}, \mathrm{I}_{2}, \mathrm{ArSCl} \ldots\right)$ developed by Larock ${ }^{4}$ and others, ${ }^{5}$ as well as transition-metal catalyzed transformations, ${ }^{6}$ played a major role in this field. In this challenging context, we recently reported the one-pot synthesis of 2-styrylindoles from ortho-substituted chloroenynes. ${ }^{7}$ In a hot toluene/MeOH mixture, using a $\mathrm{Pd}(0)$ catalyst, boronic acids and $\mathrm{K}_{2} \mathrm{CO}_{3}, 2$-alkynyldimethylanilines 1 were transformed into 2-styrylindoles after successive Suzuki arylation, ${ }^{8} \mathrm{~N}$-cyclization and $\mathrm{N}$-demethylation reactions (Scheme 1 ).

\footnotetext{
a.BioCIS, Equipe Labellisée Ligue Contre le Cancer, Univ Paris-Sud, CNRS, University Paris Saclay, 92290, Châtenay-Malabry, France

b. ATD ATG et Absorption Atomique, PLATINA, IC2MP- UMR 7285, Bat B 27-RdC Nord, 4 rue Michel Brunet, TSA 51106, 86073 Poitiers cedex 9, France

c. Institut de Chimie Moléculaire et des Matériaux d'Orsay, CNRS UMR 8182, Université Paris-Sud, Université Paris-Saclay, Bâtiment 420, 91405 Orsay cedex, France

d. Laboratoire de Chimie Moléculaire (LCM), CNRS UMR 9168, Ecole Polytechnique, IP Paris, route de Saclay, 91128 Palaiseau cedex, France

Email:vvincent.gandon@u-psud.fr, mouad.alami@u-psud.fr, olivier.provot@upsud.fr

Electronic Supplementary Information (ESI) available: [details of any supplementary information available should be included here]. See DOI: 10.1039/x0xx00000x
}

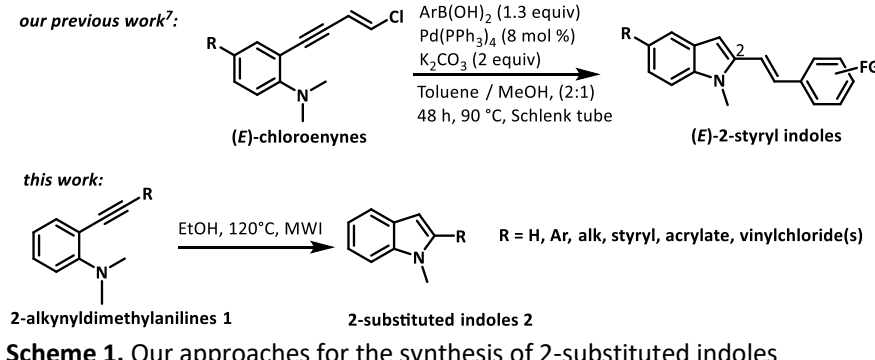

Scheme 1. Our approaches for the synthesis of 2-substituted indoles

The success of this $\mathrm{N}, \mathrm{N}$-dimethyl-cyclization $/ \mathrm{N}$-demethylation process prompted us to examine the role of each reagent in this transformation. To this end, we have removed one by one all of the reagents used in our previous protocol to transform $1 a^{8}$ into $2 a$ (Scheme 2).

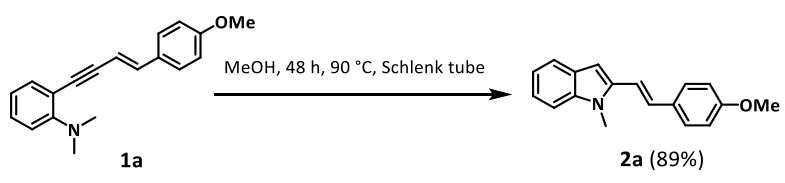

Scheme 2. Synthesis of $(E)$-2-(2-chlorovinyl)-1-methyl-1H-indole $2 \mathbf{a}$ from cyclization of 1 a followed by a $\mathrm{N}$-demethylation reaction

In the presence of only hot $\mathrm{MeOH}$, we were delighted to observe the transformation of diarylenyne $\mathbf{1 a}$ into indole $\mathbf{2 a}$ with an excellent yield $(89 \%)$. Even if the $\mathrm{N}$-cyclization of ortho-alkynylanilines into indole derivatives is well-known, to our knowledge, this result show that the formation of a 2 -substituted- $N$-methylindole can be carried out in the absence of any activating agent since a simple heating in $\mathrm{MeOH}$ is sufficient to promote the $\mathrm{N}$-cyclization and the $\mathrm{N}$ demethylation reactions. For comparison, Ribecai reported in 2009 the cyclization of 2-alkynylanilines into 2 -substituted- $1 \mathrm{H}$-indoles in water at $200^{\circ} \mathrm{C}$ under microwave heating in the absence ${ }^{9}$ or in the presence of additives ${ }^{10}$ (e.g. $\mathrm{KCl}, \mathrm{NaHCO}_{3}$, pyrrolidine,...), necessary to increase yields and the scope of the cyclization reactions.

In this paper, we wish to present our results concerning the development of this "green" annulation/demethylation process, its application to a wide range of functionalized substrates and also a possible reaction mechanism which is supported by DFT calculations. 


\section{Results and discussion}

Before studying the scope of this process using $\mathrm{EtOH}$ as only reagent we first examined the influence of other solvents on the cyclization and demethylation steps of $(E)$-chloroenyne $\mathbf{1 b}$, a poorly cooperative substrate in which the chlorine atom, useful for further transformations, ${ }^{11}$ disfavoured the 5-endo-dig annulation reaction. ${ }^{12}$ The results of this solvent and experimental screening are reported in Table 1.

Table 1. Effects of solvents and experimental conditions on the transformation of $(E)$-chloroenyne $\mathbf{1 b}$ into 2-(2-chlorovinyl)-1-methyl$1 H$-indole $\mathbf{2} \mathbf{b} .^{a}$
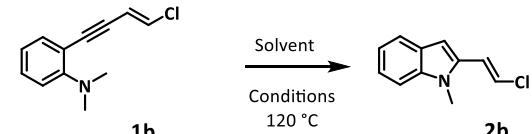

$1 b$

$2 b$

\begin{tabular}{|c|c|c|c|c|}
\hline Entry & Solvent(s) & Conditions & $\begin{array}{c}\text { Time } \\
\text { (h) }\end{array}$ & $\begin{array}{c}\text { Yield }^{b} \\
(\%)\end{array}$ \\
\hline 1 & $\mathrm{MeOH}$ & Schlenk tube & 48 & $40^{c}$ \\
\hline 2 & $\mathrm{MeOH}$ & $\mathbf{M W I}^{d}$ & 2 & 70 \\
\hline 3 & EtOH & MWI & 2 & 75 \\
\hline 4 & $i$-PrOH & MWI & 2 & 30 \\
\hline 5 & HFIP & MWI & 2 & $e$ \\
\hline 6 & Toluene & MWI & 2 & 0 \\
\hline 7 & $\mathrm{H}_{2} \mathrm{O}$ & MWI & 2 & trace \\
\hline 8 & $\mathrm{H}_{2} \mathrm{O} / \mathrm{EtOH}(1 / 1)$ & MWI & 2 & 35 \\
\hline 9 & $\mathrm{H}_{2} \mathrm{O} /$ acetone $(1 / 1)$ & $\mathrm{MWI}$ & 2 & 40 \\
\hline
\end{tabular}

${ }^{a}$ Typical reaction conditions: a mixture of $\mathbf{1 b}(0.5 \mathrm{mmol})$ was stirred in $\mathrm{EtOH}\left(3 \mathrm{~mL}\right.$ ) at $120^{\circ} \mathrm{C}$ under MWI. After completion (estimated by TLC), the mixture was allowed to cool to room temperature and $\mathrm{EtOH}$ or $\mathrm{MeOH}$ was removed under reduced pressure. The crude material was purified by silica gel column chromatography to give $\mathbf{2 b}$. ${ }^{b}$ Isolated yield. cReaction achieved at $90{ }^{\circ} \mathrm{C}$. ${ }^{d} 30 \mathrm{~W}$ Microwave irradiation. ${ }^{e}$ Complex mixture.

Under the conditions used in Scheme 2, $\mathbf{1 b}$ was transformed into indole $\mathbf{2 b}$ after $48 \mathrm{~h}$ of reaction in a poor yield of $40 \%$ (entry 1 ). Compound $\mathbf{1 b}$ was then heated in $\mathrm{MeOH}$ for $2 \mathrm{~h}$ at a higher temperature of $120{ }^{\circ} \mathrm{C}$ under microwave irradiation (MWI). Gratifyingly, after $\mathbf{2}$ h, $\mathbf{2 b}$ was isolated in $70 \%$ yield (entry 2 ). We next replaced $\mathrm{MeOH}$ by EtOH, $i-\mathrm{PrOH}$, hexafluoroisopropanol (HFIP), toluene and $\mathrm{H}_{2} \mathrm{O}$ to evaluate the influence of other solvents (entries 3-7) and found that EtOH and $\mathrm{MeOH}$ gave nearly similar yields (70 $75 \%$, entries 2,3). A more congested alcohol as $i-\mathrm{PrOH}$ allowed the expected transformation but with a poor performance $(30 \%$, entry 4 ), while the reaction run in HFIP or toluene was inefficient (entries $5,6)$. Moreover, as it could be observed in entries 7-9, water and its association with $\mathrm{EtOH}$ or acetone did not provide indole $\mathbf{2} \mathbf{b}$ with satisfactory yields. The scope of this metal- and additive-free process was then evaluated with a variety of $\mathrm{N}, \mathrm{N}$-dimethylanilines $\mathbf{1}$ bearing various alkyne substrates at the ortho-position using $\mathrm{EtOH}$ as only reagent at $120^{\circ} \mathrm{C}$ under $\mathrm{MWI}$. The results of this study are reported in Table 2. As it can be seen, under our optimal conditions, alkynes 1a, 1c-t were transformed into indoles $\mathbf{2 a}$, 2c-t with excellent yields. In details, diarylenynes $\mathbf{1 a}$ and $\mathbf{1 c}$, (di)chloroenynes $\mathbf{1 d - \mathbf { f } \text { and }}$ conjugated ethyl acrylate $\mathbf{1 g}$ reacted well in hot $\mathrm{EtOH}$ or $\mathrm{MeOH}$ (to avoid esterification, entry 7) under $\mathrm{MWI}$ to provide the expected indoles 2a, 2c-h in good yields (entries 1-7).
Table 2. Synthesis of 2-substituted indoles 2 from 2 alkynyldimethylanilines $1 .^{a}$

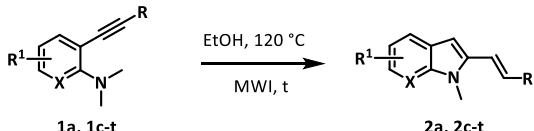

\section{1}

o-Alkynylanilines 1c-t

Indoles 2 c-s

t (h) Yield $^{b}$

$4=$

तом

2<smiles>CNc1ccccc1C#CC=Cc1ccc(C(C)=O)cc1</smiles>

1c

(1)

2a 290

3<smiles>C=CC=Cc1cc(C(=C)c2cc(OC)c(OC)c(OC)c2)ccc1N(C)C</smiles>

1d $\mathrm{Me}$<smiles>Cn1c(/C=C/c2ccc([Al])cc2)cc2ccccc21</smiles>

2c $2 \quad 90$

4<smiles>C=C(/C=C/C=C/C)/C=C/COC</smiles>

$1 e$<smiles></smiles>

2d 456<smiles>ClC=CC#Cc1ccccc1</smiles>

$1 f$<smiles>Cn1c(C=C(Cl)Cl)cc2ccccc21</smiles>

2e 6

$42^{c}$

6<smiles>[AlH2]C=[AlH2]</smiles>

7

9

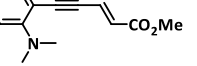

$1 \mathrm{~g}$<smiles>CCOC(=O)C=Cc1cc2ccccc2n1C</smiles>

2 2 285

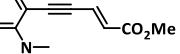

$1 \mathrm{~g}$<smiles>COC(=O)C=Cc1cc2ccccc2[nH]1</smiles>

2 g 290

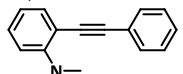

N-

$1 h$<smiles>Cn1c(-c2ccccc2)cc2ccccc21</smiles>

2h $288^{d}$<smiles>C=CC(C#Cc1ccc(OC)cc1)=CC</smiles>

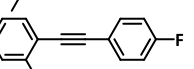

11

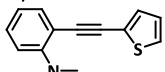

$\mathrm{N}-$

12<smiles>CNc1ccccc1C#Cc1ccccn1</smiles>

1i<smiles>Cc1ccc(-c2cccn2C)cc1</smiles>

2i $10 \quad 93$

1j<smiles>[Te]OC1CCCC1</smiles>

2j 10

$1 k$<smiles>CN1C=CC=CC1=C1C=CC=C1</smiles>

2k $10 \quad 94$

2| $10 \quad 95$

11<smiles>Cn1c(-c2ccccn2)cc2ccccc21</smiles>

2m $10 \quad 95$

13<smiles>C=CC#CC#Cc1ccc(OC)cc1</smiles><smiles>COc1ccc(C#Cc2cc3ccc([AlH+])cc3n2C)cc1</smiles>

2 2 2
14

15

16

17

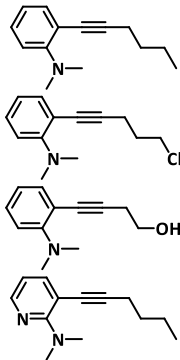

18

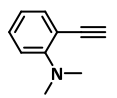

19
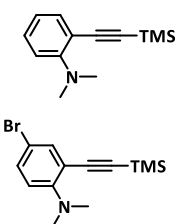

$1 n$<smiles>CCCc1cc2ccccc2n1C</smiles>

10<smiles>Cn1c(CCCCl)cc2ccccc21</smiles>

$1 p$<smiles>CCCCc1cc2ccccc2n1C</smiles>

$1 q$<smiles>CCCc1cc2cccnn2c1C</smiles>

$1 r$<smiles>Cn1ccc2ccccc21</smiles>

$1 \mathrm{~s}$<smiles>Cn1ccc2ccccc21</smiles>

$2 s$

$1 t$<smiles>Cn1ccc2cc(Br)ccc21</smiles>

$2 \mathrm{t} \quad 4$

88

${ }^{a}$ Reaction conditions are identical to those described in footnote ${ }^{a}$ of Table 1. ${ }^{b}$ Isolated yield. ${ }^{c}$ Reaction achieved at $140{ }^{\circ} \mathrm{C}$. ${ }^{d}$ Reaction achieved in $\mathrm{MeOH}$. ${ }^{e}$ Reaction achieved at $160^{\circ} \mathrm{C}$. 
Having in mind a deeper exploration of the structure-activity relationships of isoCombretastatin $\mathrm{A}^{13}$ derivatives by replacing its $\mathrm{B}$ ring with substituted-indoles, ${ }^{7,14}$ 2-chlorovinyl-indoles $\mathbf{2 d}$ and $\mathbf{2 e}$ in which the chlorine atom will be useful for further transformations, were obtained in acceptable yields regardless of the configuration of the chloroenyne double bond (entries 3, 4). Interestingly, diarylalkynes $\mathbf{1} \mathbf{h}-\mathbf{j}$, arylheteroarylalkynes $\mathbf{1 k}, \mathbf{l}$ bearing a thiophene or a pyridine moiety, and diaryldiyne $1 \mathrm{~m}$ were transformed into the expected 2-substituted indoles $\mathbf{2 i - n}$ with excellent yields (entries 813). Alkyl groups on the alkyne triple bond were also well tolerated in this process as indole derivatives $\mathbf{2 0 - \mathbf { q }}$ and azaindole $\mathbf{2} \mathbf{r}$ were obtained in good yields (entries 14-17). A terminal alkyne such as $1 \mathrm{r}$ was well tolerated to give 1 -methyl- $1 \mathrm{H}$-indole $\mathbf{2} \mathrm{s}$ in a good $89 \%$ yield (entry 18) In entries 19 and 20, we noted that silylated alkynes 1s,t were also transformed into indole derivatives $\mathbf{2 s , t}$ with good yields, but the TMS-group did not survive under these conditions. To summarize this study, this protocol is found to be practical for a variety of alkyne substrates in which a great number of functionalized group are well tolerated. Intrigued by the large scope of this transformation, we then checked that there were no traces of metals ( $\mathrm{Pd}$ and $\mathrm{Cu}$ ) in our samples since alkynes $\mathbf{1}$ were prepared according to Sonogashira and Suzuki reactions.

We thus purified diarylenyne 1i one (sample 1, S1), two (S2) and three times (S3) on silica gel. These three samples were then reacted in hot $\mathrm{EtOH}^{15}$ under $\mathrm{MWI}$, using new magnetic stir bars ${ }^{16}$ and new microwave tubes in view of their transformation into the expected 2-arylindole $\mathbf{2 i}$ (Fig. 1).

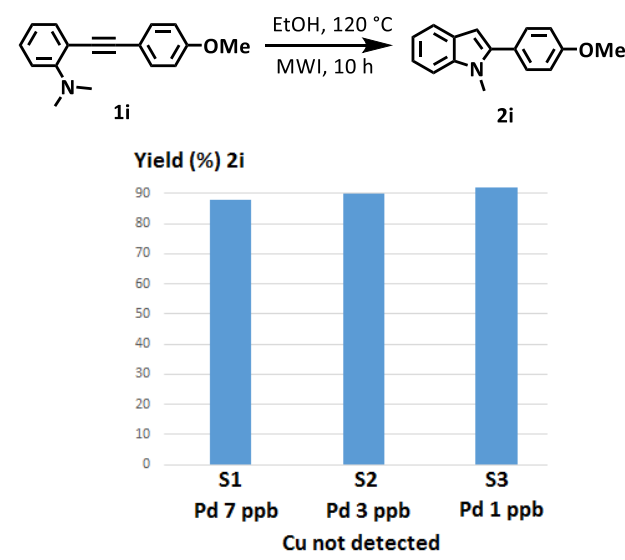

Fig 1. Synthesis of $\mathbf{2} \mathbf{i}$ from metal-free samples of $\mathbf{1 i}$

The results indicated that these samples (S1, S2 and S3) gave similar yields in $\mathbf{2 i}(88,90$ and $92 \%$ respectively). The quantity of residual traces of $\mathrm{Pd}$ and $\mathrm{Cu}$ in these samples was quantified by atomic absorption after mineralization of the samples. The results, obtained with internal standards, indicated that no traces of $\mathrm{Cu}$ in the three samples (below $5 \mathrm{ppb}$ if any) and that $\mathrm{Pd}$ quantities were also negligible (7 (S1), 3 (S2) and $1 \mathrm{ppb}$ (S3), respectively).

Encouraged by these results, we turned our attention to examining primary and secondary anilines $\mathbf{3}$ and $\mathbf{4}$ (Scheme 3).

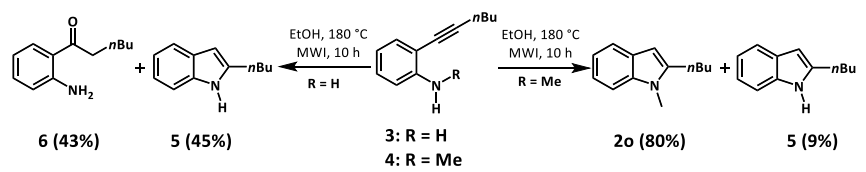

Scheme 3. Reactions of anilines $\mathbf{3}$ and $\mathbf{4}$ in hot EtOH under MWI.
As it can be seen, heating $\mathrm{N}$-methylaniline 4 at a higher temperature of $180^{\circ} \mathrm{C}$ furnished mostly indole $\mathbf{2 0}(80 \%)$ accompanied with a small quantity of $\mathrm{NH}$-indole 5 (9\%) which is consistent with our proposition of mechanism involving an ammonium intermediate and where an ethanolate anion, in this case, acted as a base rather than a nucleophile. This process is less suitable for primary anilines as $\mathbf{3}$ since indole $\mathbf{5}$ and ketone $\mathbf{6}$, resulting from the hydration of the triple bond, were obtained in equivalent quantities.

Next, we were interested to examine the behaviour of tertiary anilines 7 and $\mathbf{8}$ (Scheme 4) having respectively on their nitrogen atom, two different groups (Me and $\mathrm{Ph}$ for $\mathbf{7}, \mathrm{Me}$ and $i-\operatorname{Pr}$ for $\mathbf{8}$ ).

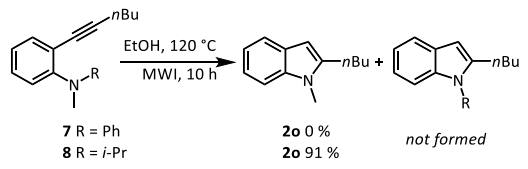

\section{Scheme 4. Cyclization attempts of anilines $\mathbf{7}$ and $\mathbf{8}$ under MWI in EtOH}

After heating 7 in $\mathrm{EtOH}$ for $10 \mathrm{~h}$ at $120^{\circ} \mathrm{C}$ under MWl irradiation, we did not observed any transformation of the poorly nucleophilic and encumbered diphenylmethylaniline $\mathbf{7}$, which was totally recovered unchanged. On the contrary, under similar conditions, a careful examination of the crude mixture by ${ }^{1} \mathrm{H}$ NMR revealed that aniline 8 was successfully transformed into $N$-methylindole $20(91 \%)$ with no trace of 2-butyl-1-isopropylindole. In this case, it is reasonable to think that the ethanolate anion formed during this process acted as base to eliminate 1-propene rather than a nucleophile (see Scheme 6).

To gain mechanistic insight into cyclization/demethylation process observed with dimethylanilines, a series of experiments was then conducted. First, $o$-hexynyldimethylaniline 1 n was heated in $\mathrm{EtOH}$ for 2 hours at $120^{\circ} \mathrm{C}$ under $\mathrm{MWI}$ in the presence of 1 equiv of 2,2,6,6tetramethylpiperidinyl- $N$-oxyl (TEMPO), a well-established radical scavenger. ${ }^{17}$ The presence of TEMPO did actually significantly alter the yield in indole $\mathbf{2 0}$ ( $84 \%$ vs $95 \%$ without TEMPO), which does not support a radical pathway.

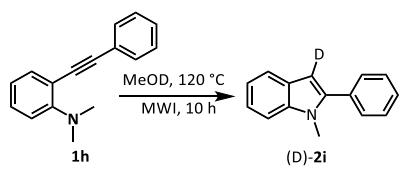

Scheme 5. Synthesis of (D)-2i

Our second interrogation concerned the activation of the alkyne triple bond as $\mathrm{EtOH}$ or $\mathrm{MeOH}$ were the only reagents used in this protocol. Therefore, we have heated diarylalkyne $\mathbf{~} \mathbf{h}$ in MeOD at $120{ }^{\circ} \mathrm{C}$ under MWI (Scheme 5). In the crude mixture, after $10 \mathrm{~h}$ of reaction, we observed the unique formation of (D)-2i indicating that MeOD may activate the alkyne triple bond of $\mathbf{1 h}$. Next, to demonstrate the fundamental role of $\mathrm{EtOH}$ or $\mathrm{MeOH}$ as being also the nucleophilic reagents responsible for the $\mathrm{N}$-demethylation step, we performed other experiments on ortho-substituted anilines $1 \mathbf{u}$ and $\mathbf{1 v}$ in which the nitrogen atom is included into a ring (Scheme 6).

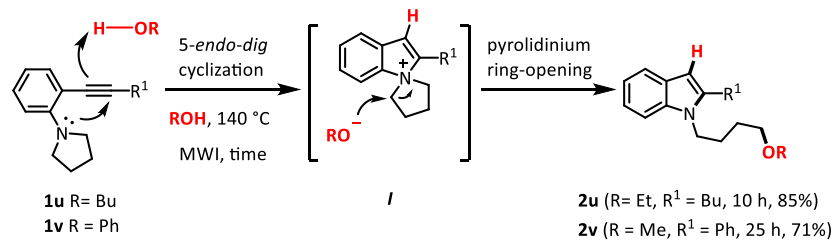

Scheme 6. Synthesis of indoles $\mathbf{2 u , v}$ and possible mechanism. 
When $\mathbf{1} \mathbf{u}, \mathbf{v}$ were heated in $\mathrm{EtOH}$ or $\mathrm{MeOH}$ under $\mathrm{MWI}$, we were very pleased to observe the formation of $\mathbf{2} \mathbf{u}$ and $\mathbf{2 v}$ demonstrating the fundamental role of $\mathrm{MeOH}$ or EtOH in the last alkylation/dealkylation steps (demethylation in the case of dimethylanilines). A possible reaction mechanism is proposed in Scheme 6 . First, the nitrogen atom of the pyrrolidine reacts with the triple bond (possibly activated by EtOH) according to a 5-endo-dig cyclization to give intermediate $I$. Then, EtOH as solvent or possibly an ethanolate species generated during the cyclization process reacts on one of the methylene groups close to the ammonium center by $\mathrm{SN}_{2}$ to open the pyrrolidinium intermediate to promote $\mathbf{2} \mathbf{u}, \mathbf{v}$.

Density functional theory (DFT) calculations were carried out to understand the origin of the activation of the substrates under the reaction conditions. The above experiments having put aside the intervention of radical species, the main issue to address was the feasibility of an ionic mechanism triggered by just the solvent. The Gaussian 09 software package was used for the calculations. ${ }^{18} \mathrm{Gas}$ phase geometry optimization was carried out at the M06-2X19/6$31 \mathrm{G}(\mathrm{d}, \mathrm{p})^{20}$ level of theory with the grid=ultrafine keyword.

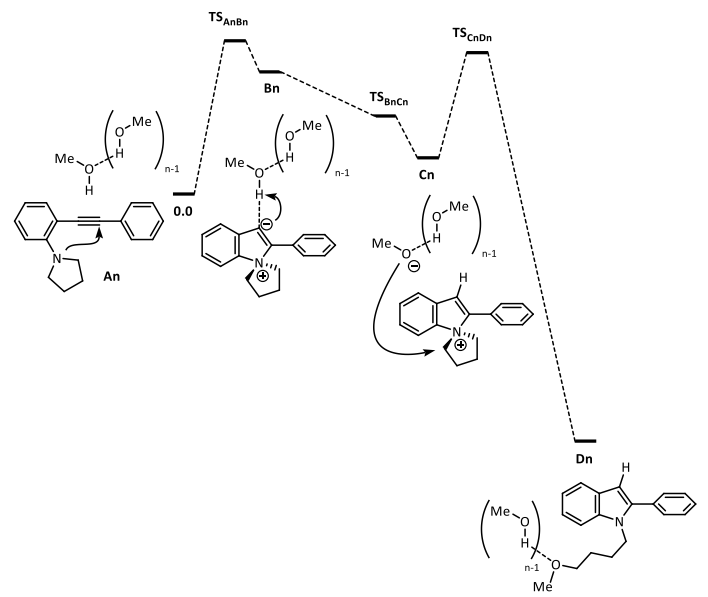

Scheme 7. Computed Steps.

Correction to the Gibbs free energy was computed at $393.15 \mathrm{~K}$. The values presented include solvent correction obtained with the $\mathrm{PCM}^{21}$ solvation model for methanol. This solvent was chosen rather than $\mathrm{EtOH}$ to save computer time, as it provides similar experimental results. The model substrate is presented in Scheme 7. Its cyclization was studied in the presence of $\mathrm{H}$-bonded methanol clusters $(\mathrm{MeOH})_{n}$ of various sizes $(n=1-6) .{ }^{22}$ Linear clusters were privileged to be able to bridge the reactive sites. We found three steps starting from the molecular system An comprising the substrate and $(\mathrm{MeOH})_{n}$ optimized together: i) a 5-endo-dig cyclization yielding the vinyl anion ammonium species $\mathrm{Bn}$, ii) a proton transfer from the $(\mathrm{MeOH})_{n}$ cluster to the vinyl anion center to give the $\mathrm{H}$-bonded methylate/ammonium species $\mathrm{Cn}$, and iii) $\mathrm{SN}_{2}$ reaction to give the final dealkylated product Dn.

The relative free energies of the computed intermediates and transition states are collected in Table 3 as a function of $n$, taking An as a reference. With only one $\mathrm{MeOH}$ molecule $(n=1)$, the cyclization of A1 into B1 requires a high free energy of activation of 29.9 $\mathrm{kcal} / \mathrm{mol}$ and is markedly endergonic by $27.2 \mathrm{kcal} / \mathrm{mol}$. No other steps could be computed. With $\mathrm{n}=2$, the first barrier is $26.4 \mathrm{kcal} / \mathrm{mol}$, which is significantly lower than with $n=1$. The cyclization is endergonic by $23.4 \mathrm{kcal} / \mathrm{mol}$. The deprotonation step could not be computed. The $\mathrm{SN}_{2}$ step was achieved through a transition state lying at $26.9 \mathrm{kcal} / \mathrm{mol}$ above A2. Product D2 is obtained in a strongly exergonic fashion, as it lies $38.7 \mathrm{kcal} / \mathrm{mol}$ below $\mathbf{A 2}$. With $\mathrm{n}=3-6$, the full pathway could be calculated. It can be seen that the ratedetermining step is the first one in all cases. The lowest barrier for this first step is $24.4 \mathrm{kcal} / \mathrm{mol}$. It corresponds to a cluster of $4 \mathrm{MeOH}$. Clearly, the formation of a network of $\mathrm{H}$-bonded molecules has a positive impact on the cyclization, but the effect is not linear as the barrier increases with $n>4$. Focusing on $n=4$, the cyclization step is endergonic by $18.5 \mathrm{kcal} / \mathrm{mol}$ (Scheme 8 ). The next step, the proton transfer connecting $\mathbf{B} \mathbf{4}$ to $\mathbf{C 4}$, is achieved through a transition state that has a lower energy than B4. This unusual situation is typical of what is referred to as a collapse mechanism and means that B4 is a very unstable intermediate, which, if it exists, is immediately transformed into $\mathbf{C 4}$. This species is less stable than A4 by 3.6 $\mathrm{kcal} / \mathrm{mol}$. What funnels the reaction towards the final product is the dealkylation step. The corresponding transition state TS $_{\text {C4D4, lies }} 20.2$ $\mathrm{kcal} / \mathrm{mol}$ above A4. This step is strongly exergonic, D4 being located at $-35.2 \mathrm{kcal} / \mathrm{mol}$ on the free energy surface. Overall, the calculated free energies of activation are realistic with regard to the experimental conditions and the reaction is a highly favorable process. The free energy profile and the geometry of the intermediates and transition states with $\mathrm{n}=4$ are displayed in Scheme 8. The $\mathrm{MeOH}$ molecule that donates its proton to the vinyl anion does not become the methanolate of the cluster. It is simultaneously reprotonated by the nearby $\mathrm{MeOH}$ molecule, which is in turn reprotonated by the third one. The proton transfer stops here, leaving the third molecule of the cluster as a doubly $\mathrm{H}$-bonded methanolate. The $\mathrm{SN}_{2}$ step could not be achieved from this methanolate but from the less hindered tail $\mathrm{MeOH}$, which is simultaneously deprotonated by the methanolate. Looking at higher clusters in Table $3(n=5,6)$, similar characteristics can be drawn, notably regarding the instability of $\mathbf{B n}$ and its straightforward collapse to $\mathrm{Cn}$. However, the $\mathrm{n}=4$ case appears to be the best compromise in terms of free energy for the entire process. This does not mean that only linear $(\mathrm{MeOH})_{4}$ clusters are active species in solution for this reaction, but the feasibility of an ionic mechanism based on the simple activation of the substrate by methanol aggregates is validated by these computations.

\section{Conclusions}

In summary, a variety of 2-substituted indoles $\mathbf{2}$ were prepared in high yields from the annulation/demethylation process of 2alkynyldimethylanilines. A simple heating of these compounds readily accessible in EtOH allowed rapid and efficient access to various $\mathrm{N}$-methylindoles with high yields. This approach, which does not require metal catalysts or additives, and which is applicable to different types of alkynes bearing various functional groups, is in perfect harmony with the requirements of modern environmentally friendly chemistry.

\section{Conflicts of interest}

There are no conflicts to declare.

\section{Acknowledgments}

Authors gratefully acknowledge support of this project by CNRS, Univ. Paris-Sud, and by La Ligue Nationale Contre le Cancer through an Equipe Labellisée 2014 grant. Guangkuan Zhao thank the Chinese Scholarship Council for Ph.D. fundings. Our laboratory is a member of the laboratory of excellence LERMIT supported by a grant from ANR (ANR-10-LABX-33). 


\section{COMMUNICATION}

Table 3. Free energies $\left(\Delta G_{393}, \mathrm{kcal} / \mathrm{mol}\right)$ of the computed species shown in Scheme 7.

\begin{tabular}{ccccccc}
\hline $\mathrm{n}$ & $\mathrm{TS}_{\text {AnBn }}$ & $\mathbf{B n}$ & SS $_{\text {BnCn }}$ & Cn & TS $_{\text {CnDn }}$ & Dn \\
\hline 1 & 29.9 & 27.2 & - & - & - & - \\
2 & 26.4 & 23.4 & - & 16.7 & 26.9 & -38.7 \\
3 & 26.0 & 20.0 & 14.8 & 8.1 & 24.1 & -39.2 \\
4 & 24.4 & 18.5 & 15.1 & 3.6 & 20.2 & -35.2 \\
5 & 28.3 & 20.8 & 18.2 & 3.0 & 19.9 & -31.5 \\
6 & 27.5 & 19.5 & 16.3 & 1.7 & 22.9 & -28.6 \\
\hline
\end{tabular}

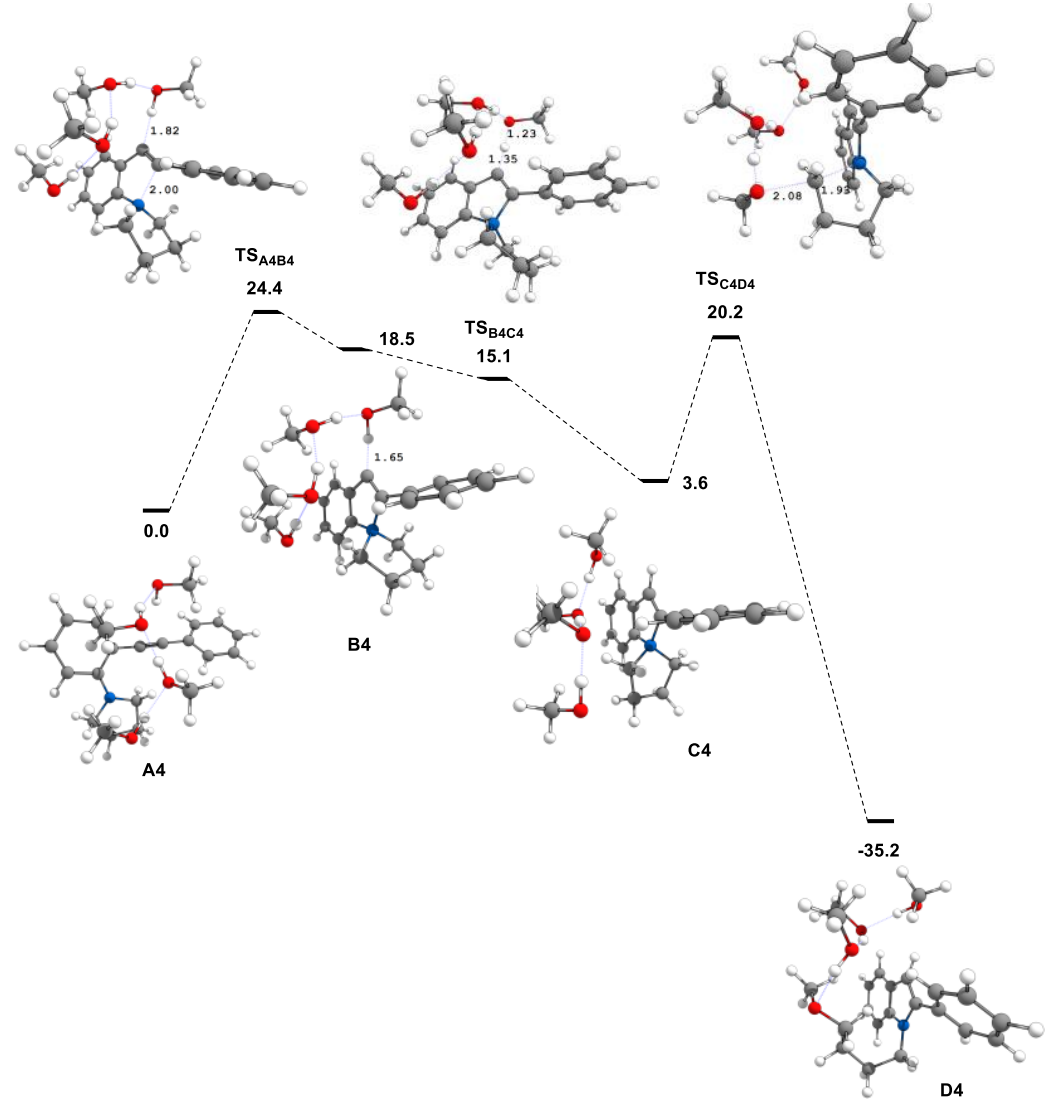

Scheme 8. Free energy profile $\left(\Delta G_{393}, \mathrm{kcal} / \mathrm{mol}\right)$ for $\mathrm{n}=4$; Geometry of the intermediates and transition states (distances in $\AA$ )

\section{References}

1 (a) J. A. Homer, J. Sperry, J. Nat. Prod., 2017, 80, 2178-2187. (b) M. Ishikura, T. Abe, T. Choshi, S. Hibino, Nat. Prod. Rep., 2015, 32, 1389-1471. (c) A. J. Kochanowska-Karamyan, M. T. Hamann, Chem. Rev., 2010, 110, 4489-4497. (d) T. Kawasaki, K. Higuchi, Nat. Prod. Rep., 2005, 22, 761-793. (e) M. Z. Zhang, Q. Chen, G. F. Yang, Eur. J. Med. Chem., 2015, 89, 421-441.

2 (a) D. Bardiot, M. Koukni, W. Smets, G. Carlens, M. McNaughton, S. Kaptein, K. Dallmeier, P. Chaltin, J. Neyts, A. Marchand, J. Med. Chem., 2018, 61, 8390-8401. (b) G. Luo, L. Chen, A. Easton, A. Newton, C. Bourin, E. Shields, K. Mosure,
M. G. Soars, R. J. Knox, M. Matchett, R. L. Pieschl, D. J. PostMunson, S. Wang, J. Herrington, J. Graef, K. Newberry, D. V. Sivarao, A. Senapati, L. J. Bristow, N. A. Meanwell, L. A. Thompson, C. Dzierba, J. Med. Chem., 2019, 62, 831-856. (c) Y. Baqi, T. Pillaiyar, A. Abdelrahman, O. Kaufmann, S. Alshaibani, M. Rafehi, S. Ghasimi, R. Akkari, K. Ritter, K. Simon, A. Spinrath, E. Kostenis, Q. Zhao, M. Köse, V. Namasivayam, C. E. Müller, J. Med. Chem., 2018, 61, 8136-8154.

3 (a) N. K. Kaushik, N. Kaushik, P. Attri, N. Kumar, C. H. Kim, A. K. Verma, E. H. Choi, Molecules, 2013, 18, 6620-6662. (b) M. J. Naim, O. Alam, M. J. Alam, F. Bano, P. Alam, N. Shrivastava, IJPSR, 2016, 7, 51-62. 
4 (a) D. Yue, R. C. Larock, Org. Lett., 2004, 6, 1037-1040. (b) Y. Chen, F. Shi, R. C. Larock, J. Org. Chem., 2009, 74, 6802-6811. (c) D. Yue, T. Yao, R.C. Larock, J. Org. Chem., 2006, 71, 62-69. (d) T. Yao, D. Yue, R. C. Larock, J. Org. Chem., 2005, 70, 99859989.

5 (a) R. W. H. ten Hoedt, G. van Koten, J. G. Noltes, Synth. Commun., 1977, 7, 61-69. (b) N. A. Danilkina, A. E. Kulyashova, A. F. Khlebnikov, S. Bräse, I. A. Balova, J. Org. Chem., 2014, 79 9018-9045. (c) J. Meesin, M. Pohmakotr, V. Reutrakul, D. Soorukram, P. Leowanawat, C. Kuhakarn, Org. Biomol. Chem. 2017, 15, 3662-3669. (d) C. C. Chen, S. C. Yang, M. J. Wu, J. Org. Chem., 2011, 76, 10269-10274. (e) X. Zhang, Y. He, S. Liu, Z. X. Jiang, Z. Yang, Y. Dong, S. C. Nabinger, L. Wu, A. M Gunawan, L. Wang, R. C. Chan, Z. Y. Zhang, J. Med. Chem., 2010, 53, 2482-2493.

6 (a) K. Krüger, A. Tillack, M. Beller, Adv. Synth. Catal., 2008, 350, 2153-2167. (b) H. E. Ho, K. Oniwa, Y. Yamamoto, T. Jin, Org. Lett., 2016, 18, 2487-2490. (c) A. Sperança, B. Godoi, P. H. Menezes, G. Zeni, Synlett, 2013, 24, 1125-1132. (d) X. Zeng, R. Kinjo, B. Donnadieu, G. Bertrand, Angew. Chem. Int. Ed., 2010, 49, 942-945. (e) E. A. Filatova, A. F. Pozharskii, A. V. Gulevskaya, V. A. Ozeryanskii, J. Org. Chem., 2015, 80, 872881.

7 G. Zhao, J. Bignon, H. Levaique, J. Dubois, M. Alami, O. Provot, J. Org. Chem., 2018, 83, 15323-15332.

8 Diarylenynes were prepared at $90^{\circ} \mathrm{C}$ after $7 \mathrm{~h}$ of reaction, see: A. Tikad, A. Hamze, O. Provot, J. D. Brion, M. Alami, Eur. J. Org. Chem., 2010, 725-731.

9 A. Carpita, A. Ribecai, Tetrahedron Lett., 2009, 50, 6877-6881.

10 A. Carpita, A. Ribecai, P. Stabile, Tetrahedron, 2010, 66, 71697178.

11 (a) M. Seck, X. Franck, R. Hocquemiller, B. Figadère, J. F. Peyrat, O. Provot, J. D. Brion, M. Alami, Tetrahedron Lett., 2004, 45, 1881-1884. (b) M. Dos Santos, X. Franck, R. Hocquemiller, B. Figadère, J. F. Peyrat, O. Provot, J. D. Brion, M. Alami, Synlett, 2004, 15, 2697-2700. (c) G. Zhao, M. Alami, O. Provot, RCS Adv., 2017, 7, 46007-46013.

12 G. Zhao, L. Z. Yuan, M. Roudier, J. F. Peyrat, A. Hamze, J. D. Brion, O. Provot, M. Alami, Synthesis, 2016, 48, 3382-3392.

13 (a) S. Messaoudi, B. Tréguier, A. Hamze, O. Provot, J. F. Peyrat, M. Liu; J. Bignon, J. Wdzieczak-Bakala, S. Thoret, J. Dubois, J. D. Brion, M. Alami, J. Med. Chem., 2009, 52, 4538-4542. (b) O. Provot, A. Hamze, J. F. Peyrat, J. D. Brion, M. Alami, Anticancer Agents Med. Chem., 2013, 13, 1614-1635 and references therein.

14 For recent references, see: (a) T. Naret, I. Khelifi, O. Provot, J. Bignon, H. Levaique, J. Dubois, M. Source, A. Kasselouri, A. Deroussent, A. Paci, P. F. Varela, B. Gigant, M. Alami, A. Hamze, J. Med. Chem., 2019, 62, 1902-1916. (b) I. Khelifi, T. Naret, A. Hamze, J. Bignon, H. Levaique, M. C. Garcia Alvarez, J. Dubois, O. Provot, M. Alami, Eur. J. Med. Chem., 2019, 168, 176-188.

15 Achieving these cyclization reactions under an argon atmosphere with a degassed and freshly distilled EtOH solution to eliminate traces of additives, had no impact on the outcome and the yield of these transformations.

16 It has been recently demonstrated that residual traces of metals can come from the destruction and contaminationtrapping effects of magnetic stir bars, see: E. O. Pentsak, D. B. Eremin, E. G. Gordeev, V. P. Ananikov, ACS Catal., 2019, 9, 3070-3081.

17 J. F. K. Keana, Chem. Rev., 1977, 78, 37-64.

18 M. J. Frisch, G. W. Trucks, H. B. Schlegel, G. E. Scuseria, M. A. Robb, J. R. Cheeseman, G. Scalmani, V. Barone, B. Mennucci, G. A. Petersson, H. Nakatsuji, M. Caricato, X. Li, H. P. Hratchian, A. F. Izmaylov, J. Bloino, G. Zheng, J. L. Sonnenberg, M. Hada, M. Ehara, K. Toyota, R. Fukuda, J. Hasegawa, M. Ishida, T. Nakajima, Y. Honda, O. Kitao, H. Nakai, T. Vreven, J.
A. Montgomery Jr, J. E. Peralta, F. Ogliaro, M. Bearpark, J. J. Heyd, E. Brothers, K. N. Kudin, V. N. Staroverov, T. Keith, R. Kobayashi, J. Normand, K. Raghavachari, A. Rendell, J. C. Burant, S. S. Iyengar, J. Tomasi, M. Cossi, N. Rega, J. M. Millam, M. Klene, J. E. Knox, J. B. Cross, V. Bakken, C. Adamo, J. Jaramillo, R. Gomperts, R. E. Stratmann, O. Yazyev, A. J. Austin, R. Cammi, C. Pomelli, J. W. Ochterski, R. L. Martin, K. Morokuma, V. G. Zakrzewski, G. A. Voth, P. Salvador, J. J. Dannenberg, S. Dapprich, A. D. Daniels, O. Farkas, J. B. Foresman, J. V. Ortiz, J. Cioslowski and D. J. Fox, Gaussian 09, revision D.01, Gaussian, Inc., Wallingford CT, 2013.

19 Y. Zhao, D. G. Truhlar, J. Chem. Phys., 2006, 125, 194101-18.

20 (a) A. D. MacLean and G. S. Chandler, J. Chem. Phys., 1980, 72 5639-5648. (b) R. Krishnan, J. S. Binkley, R. Seeger, J. A. Pople, J. Chem. Phys,. 1980, 72, 650-654.

21 G. Scalmani, M. J. Frisch, J. Chem. Phys., 2010, 132, 11411015.

22 S. L. Boyd, R. J. Boyd, J. Chem. Theory Comput., 2007, 3, 54-61. 